\title{
Aprenda+ no ENEM: importante recurso pedagógico e tecnológico utilizado como fonte facilitadora da inclusão do aluno do Ensino Médio através da aprendizagem digital
}

\author{
Norma Alves de Sales Santos ${ }^{1}$, Pedro Henrique Do Nascimento Esteves ${ }^{2}$, Gustavo \\ de Oliveira Andrade ${ }^{3}$, \\ ${ }^{1}$ Universidade Aberta do Brasil (UAB) \\ Rio de Janeiro - RJ \\ ${ }^{1}$ Universidade Estadual do Norte Fluminense Darcy Ribeiro (UENF) \\ Campos dos Goytacazes - RJ \\ ${ }^{1}$ Instituto Federal do Espírito Santo (IFES) \\ Barra de São Francisco - ES \\ normaassantos@gmail.com; pedrohne@yahoo.com.br; \\ gustavo.andradelifes.edu.br
}

\begin{abstract}
Resumo. Este artigo tem por objetivo apresentar Aprenda+ no ENEM. Tratase de um recurso pedagógico que agrega tecnologia, ferramentas lúdicas e conteúdos básicos da matriz curricular do Ensino Médio. Em formato de um sistema a ser utilizado por pessoas portadoras de certificação ou alunos ainda matriculados no Ensino Médio, tem por objetivo solidificar a aprendizagem sistematizada oferecida pelas instituições regulares de ensino. A utilização através de aparelhos de celular torna o aplicativo acessível aos usuários que, motivados pelos aspectos lúdicos e de fácil manuseio, não terão dificuldades em seus estudos. Constitui-se em uma importante ferramenta para os estudantes que buscam aprovação no ENEM.
\end{abstract}

\section{Cenário de uso}

Segundo o Instituto Nacional de Estudos e Pesquisas Educacionais Anísio Teixeira INEP, o exame nacional do ensino médio - ENEM, em 2016, possui 7.173.574 inscritos. A faixa etária dos candidatos inscritos em 2015 oscilou entre 18 e 30 anos, sendo a maioria concluintes do Ensino Médio. Percebe-se que o desafio em busca da preparação se torna ainda maior, uma vez que o ciclo para a formação educacional já se encontra completo, sem o contato diário e direto com os docentes.

O Aprenda+ no ENEM é um sistema portátil e de fácil acesso, com recursos audiovisuais, onde o usuário poderá se atualizar e revisar os conteúdos inseridos no aplicativo, tais como linguagens, códigos e suas tecnologias, que abrange o conteúdo de Língua Portuguesa (Gramática, Ortografia e Literatura); Língua Estrangeira Moderna; Artes; Educação Física; Tecnologias da Informação; Matemática e suas tecnologias; Ciências da Natureza e suas tecnologias, que abrange os conteúdos de Química, Física e Biologia; Ciências Humanas e suas tecnologias, que abrange os conteúdos de Geografia, História, Filosofia, Sociologia e conhecimentos gerais. 
Por sua gratuidade e portabilidade, o Aprenda + permite acessibilidade em toda a rede nacional de ensino, podendo ser executado em dispositivos eletrônicos tais como tablets, celulares ou qualquer dispositivo disponível que possua sistema operacional com navegador web atualizado. Abrangendo grande parte das disciplinas conforme as Diretrizes Curriculares Nacionais da Educação Básica, o aplicativo tem potencial para ser utilizado em escolas, cursos e demais locais de ensino, inclusive em salas de aprendizagem virtuais, uma vez que seu desenvolvimento foi baseado em linguagem de programação web padronizada em sua mais nova versão.

\section{Desenvolvimento}

O Aprenda + no ENEM foi idealizado levando-se em consideração quatro etapas do processo de desenvolvimento, sendo o levantamento de requisitos responsável por catalogar os aplicativos semelhantes, destinados a testar os conhecimentos dos conteúdos exigidos na prova, identificando as necessidades dos usuários que procuram além do conhecimento, aplicativos que sejam interativos, atrativos, fáceis de utilizar e que tenham qualidade e desempenho. A análise inicial foi destinada a traçar o escopo do aplicativo, considerando a escolaridade do público-alvo, design proposto, facilidade na implementação, seleção da ferramenta na qual o aplicativo foi desenvolvido e, por último, a fase de teste, responsável por testar a performance do aplicativo. Vale destacar que os testes iniciais foram realizados pela própria equipe de desenvolvimento durante a concepção do aplicativo e, em seguida, validada por professores convidados de acordo com área e especialidade.

A tecnologia HTML5 (Hypertext Markup Language, versão 5) permite que o Aprenda+ no ENEM seja acessado por dispositivos móveis e também por navegadores de internet. O HTML5 é uma evolução do HTML com novos recursos e tecnologias que facilitam o desenvolvimento de soluções web, apresentando melhorias significativas como: funcionalidades de semântica, acessibilidade, suporte aos mais recentes conteúdo multimídias (BOTELHO, 2011). Já em relação ao design adotado para construção da identidade visual do aplicativo, utilizou-se a combinação de dois softwares, sendo o Adobe Photoshop, em sua versão CC 2014 e o Corel Draw, versão X7.

Para utilização do aplicativo por meio de dispositivos móveis, é necessário fazer o download pela loja de aplicativos do Google, ainda está em fase de inserção e disponibilização. Alguns ajustes estão sendo realizados como: criação de usuários para facilitar o histórico de suas ações e controle de estudos dentro do aplicativo. Serão realizados estudos direcionados, com vistas a que o usuário tenha a possibilidade de selecionar a disciplina onde possui maior dificuldade de aprendizagem, ampliação do banco de questões para que os usuários possam selecionar as questões por meio das categorias definidas pelo MEC, dentre elas: Ciências da Natureza, Ciências Humanas, Linguagens e Matemática.

O banco de dados que compõe o Aprenda + no ENEM possui questões inspiradas e extraídas dos melhores simulados e fontes confiáveis que legitimam sua qualidade e eficiência. Todavia, ainda não é possível mensurar os impactos do Aprenda+ no ENEM no que se refere à aprendizagem e aceitação por parte dos alunos, uma vez que o mesmo encontra-se em fase de finalização e inserção de novos recursos e funcionalidades. Espera-se que no segundo semestre de 2016, o Aprenda+ no ENEM esteja disponível na loja Google, de forma gratuita, para que possa ser utilizado a 
V Congresso Brasileiro de Informática na Educação (CBIE 2016)

Anais dos Workshops do V Congresso Brasileiro de Informática na Educação (CBIE 2016)

qualquer momento e em qualquer lugar, com o objetivo de facilitar os estudos dos usuários que buscam avançar em seu processo de aprendizagem

\section{Apresentação do Software}

O Aprenda+ no ENEM é um sistema portátil e de fácil acesso, desenvolvido com a finalidade de oferecer suporte pedagógico aos usuários detentores de certificação no Ensino Médio. Os recém certificados podem intensificar as aprendizagens adquiridas ao longo dos três anos de escolaridade e aqueles que se sentirem inseguros quanto à internalização de alguns conhecimentos podem buscar essa complementação. Existe também as pessoas que possuem certificação de longo período e que precisam fazer revisão dos conteúdos já esquecidos. Logo, o Aprenda+ no ENEM se apresenta como um recurso didático que atende bem às expectativas de ambos os públicos.

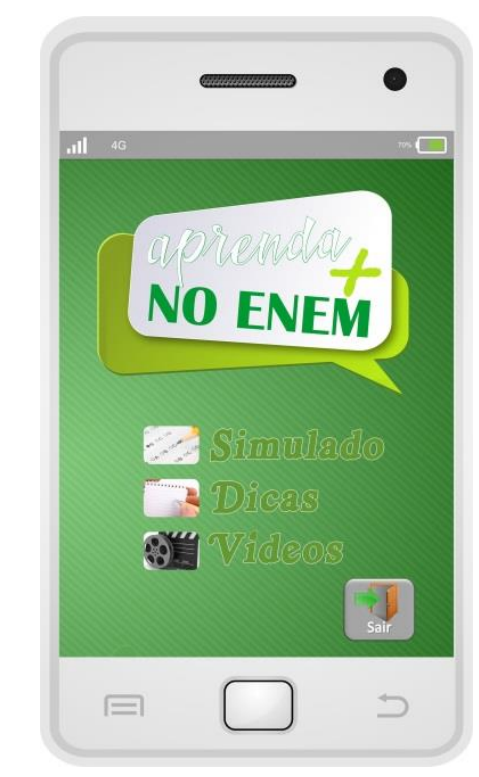

Figura 1: Tela inicial do "Aprenda+ no ENEM"

A Figura 1 identifica o aplicativo Aprenda+ no ENEM e os recursos disponíveis 
V Congresso Brasileiro de Informática na Educação (CBIE 2016)

Anais dos Workshops do V Congresso Brasileiro de Informática na Educação (CBIE 2016)

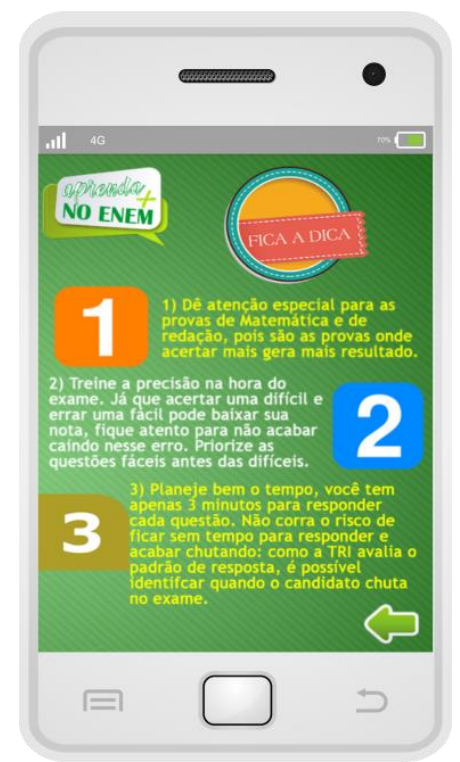

Figura 2: Dicas - "Aprenda+ no ENEM"

A Figura 2 apresenta exemplos de "dicas" fornecidas para a aprendizagem

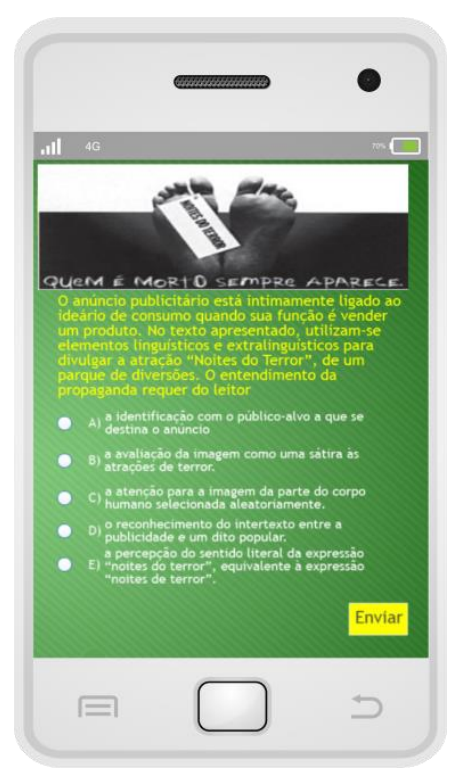

Figura 3: Simulado - "Aprenda+ no ENEM"

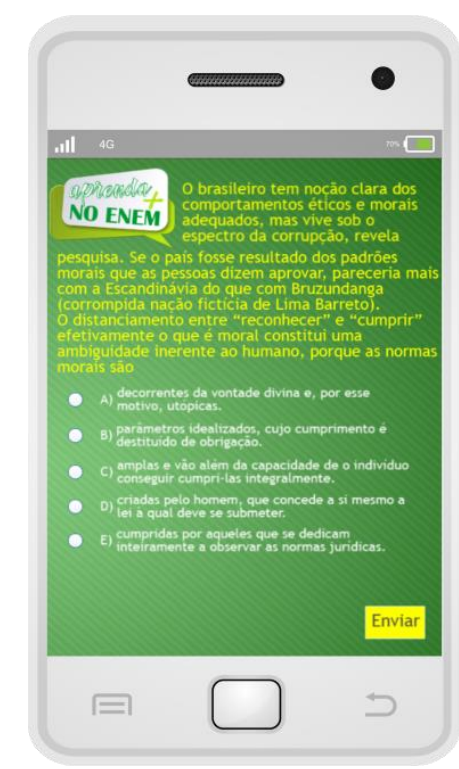

Figura 4: Simulado - "Aprenda+ no ENEM"

As Figuras 3 e 4 fornecem exemplos de exercícios de fixação de conteúdos 
V Congresso Brasileiro de Informática na Educação (CBIE 2016)

Anais dos Workshops do V Congresso Brasileiro de Informática na Educação (CBIE 2016)

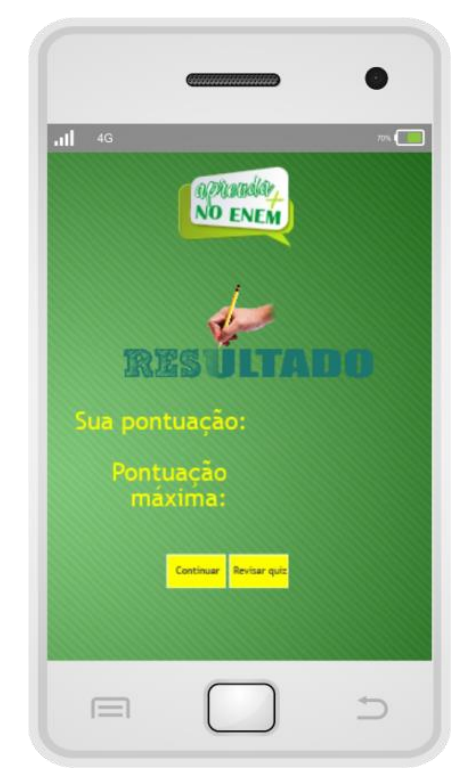

Figura 5: Simulado - "Aprenda+ no ENEM"

A Figura 5 reproduz a pontuação obtida pelo usuário ao final das respostas dadas.

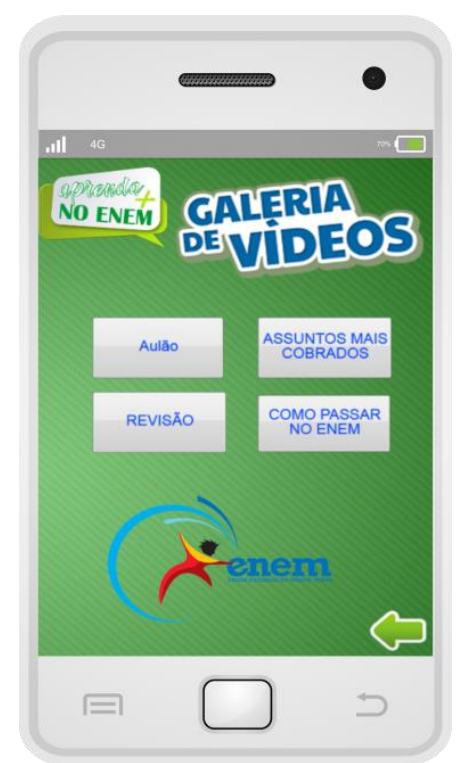

Figura 6: Vídeos - "Aprenda+ no ENEM"

A Figura 6 contém opções complementares de vídeos pedagógicos

\section{Considerações finais}

Além dos alunos com certificação recente, existem os que ainda estão cursando o Ensino Médio, e também aqueles que há anos terminaram o referido curso e que retomam os estudos com o objetivo de complementação escolar para futura inserção na 
V Congresso Brasileiro de Informática na Educação (CBIE 2016)

Anais dos Workshops do V Congresso Brasileiro de Informática na Educação (CBIE 2016)

graduação. Portanto, o Aprenda+ no ENEM vem oferecer a esse grupo de estudantes mais um recurso pedagógico com o intuito de solidificar a aprendizagem e ao mesmo tempo prepará-los para o Exame Nacional do Ensino Médio - ENEM.

As estatísticas apontam para um grande quantitativo de pessoas nesse nível de escolarização e são muitas as razões que aproximam esse público da busca ou retomada dos conteúdos pertencentes à matriz curricular do Ensino Médio. O Aprenda+ no ENEM surge para suprir essa lacuna existente na oferta de aprendizagem e apresenta opções concretas para atender aos anseios dos alunos que buscam aprofundar seus conhecimentos.

A inserção no mercado de trabalho está cada vez mais competitiva, logo, tornase necessário oferecer ao estudante a possibilidade de solidificar o nível de escolarização básica para que possa atingir níveis mais altos de conhecimento, através de uma graduação. A oferta de aprendizagens significativas requer a utilização de recursos como Aprenda+ no ENEM que possibilitem a concretização desse processo educativo.

\section{Referências}

BOTELHO, R. (2011). As novidades do HTML5. Disponível em: http:/www.devme dia.com.br/as-novidades-do-html5/23992. Acesso em: 09 jun. 2016.

INEP. (2016). Total de inscritos no Enem cresce $24 \%$ em relação à última edição. Disponível em: http://portal.inep.gov.br/rss_enem/-/asset_publisher/oV0H/ content/id/112749. Acesso em: 23 jun. 2016. 